\title{
Corrective spinal surgery may be protective against stroke in patients with blunt traumatic vertebral artery occlusion
}

\author{
Paul M. Foreman, MD, ${ }^{1}$ Christoph J. Griessenauer, MD, ${ }^{1}$ Michelle Chua, BS, ${ }^{2}$ Mark N. Hadley, MD, ${ }^{1}$ \\ and Mark R. Harrigan, MD' \\ ${ }^{1}$ Department of Neurosurgery, University of Alabama at Birmingham, Alabama; and ${ }^{2}$ Harvard Medical School, Harvard University, \\ Boston, Massachusetts
}

OBJECT Approximately $10 \%$ of patients with blunt traumatic extracranial cerebrovascular injury have a complete occlusion of the vertebral artery (VA). Ischemic stroke due to embolization of thrombus from an occluded VA following cervical spine surgery has been observed. The risk of ischemic stroke with cervical spine surgery in the presence of an occluded VA, however, has never been determined.

METHODS A retrospective chart review of 52 patients with a VA occlusion following a blunt trauma was performed. Clinical and radiographic characteristics were collected and analyzed.

RESULTS Ten patients (19.2\%) suffered an ischemic stroke attributable to a traumatic VA occlusion. Univariate analysis demonstrated that patients with ischemic stroke were significantly older $(p=0.042)$ and had a lower rate of cervical spine surgery $(p<0.005)$. Multivariate analysis found cervical spine surgery to be protective against ischemic stroke (OR 0.049 [95\% Cl 0.014-0.167], $p=0.014$ ); increasing age and bilateral VA injury (bilateral occlusion or unilateral occlusion with contralateral dissection) were risk factors for ischemic stroke (OR 1.05 [95\% Cl 1.02-1.07], p = 0.065 and OR 13.2 [95\% Cl 2.98-58.9], $p=0.084$, respectively).

CONCLUSIONS Traumatic VA occlusion is associated with a risk of ischemic stroke and mortality. Corrective cervical spine surgery potentially decreases the risk of ischemic stroke by stabilizing the spine and thereby reducing motion across the occluded segment of the VA and preventing embolization of thrombus. While a high stoke risk may be inherent to the disease, novel therapies should be investigated.

http://thejns.org/doi/abs/10.3171/2015.1.SPINE141174

KEY WORDS stroke; trauma; spine surgery; vertebral artery occlusion; spine fracture; dissection; vascular disorders

$\mathrm{T}$ RAUMATIC vertebral artery (VA) injury accounts for nearly half of all traumatic cerebrovascular injury (TCVI) and is often associated with a cervical spine fracture. Traumatic occlusion (Type IV TCVI) of the VA occurs in $7.1 \%-19.7 \%$ of patients with a cervical spine injury $4,7,15$ and carries a risk of vertebrobasilar ischemia through mechanisms of hemodynamic failure, or more commonly, distal embolization of thrombus. The incidence of ischemic stroke in this setting ranges from $7.1 \%$ to $33.3 \%{ }^{1,10,12,14}$ Anecdotal evidence suggests that cervical spine manipulation (i.e., closed reduction, surgery) in the presence of a traumatic VA occlusion increases the risk of embolization and ischemic stroke. However, some authors believe that surgical fixation of the cervical spine decompresses the injured vessel and may avoid thrombus propagation, thereby reducing the risk of ischemic stroke. ${ }^{11,16}$

A relative lack of data regarding risk of ischemic stroke in the setting of a traumatic VA occlusion with an operative spine injury has led to wide variability in practice ranging from treatment with antiplatelets to prophylactic endovascular occlusion of the occluded VA. A series of 52 patients with traumatic VA occlusions are presented with particular attention to ischemic stroke and cervical spine intervention. 


\section{Methods}

A retrospective medical record review was performed in 54 patients with known traumatic VA occlusion identified between 2008 and 2013 at a Level I trauma center. Two patients were excluded due to a penetrating mechanism of injury (1 gun shot wound and 1 knife stab wound). Thus 52 patients with VA occlusion due to high-energy blunt trauma were included. Follow-up included only the inpatient hospitalization period. This investigation was approved by the institutional review board.

All blunt trauma patients with established risk factors for TCVI undergo screening neck CT angiography (CTA). All consecutive patients with screening CTA indicating a traumatic VA occlusion between 2008 and 2013 were included. Clinical and radiographic data about each patient were collected and evaluated. Basic demographic information, mechanism of injury, and TCVI risk factors prompting the screening CTA of the neck were obtained from trauma records. All cervical spine injuries were studied using thin-slice CT with or without MRI. All images were reviewed by at least 1 neurosurgeon in consultation with an attending radiologist's final interpretation. A cervical spine fracture was defined as a cortical discontinuity involving any portion of the vertebra. Subluxation was defined as a malalignment of the bony elements and included frank dislocation; minor or questionable malalignment that did not necessitate treatment was not considered a subluxation. The management of the cervical spinal injuries were determined by either orthopedic or neurosurgical staff in conjunction with the trauma service. Halo application was performed following standard procedure for halo ring application and vest fitting. Closed reduction is defined as cervical traction via hanging weight with the goal of cervical realignment. The orthopedic or neurosurgical staff determined the approach and specifics of the operative intervention.

Ischemic stroke was diagnosed on CT with evidence of hypoattenuation or MRI with diffusion restriction and an apparent diffusion correlation correlate in a vascular territory corresponding to the occluded VA. All images were reviewed by at least one neurosurgeon in consultation with an attending radiologist's final interpretation. Ischemic strokes were classified as symptomatic when there was documentation of neurological deficits or death attributable to vertebrobasilar ischemia.

Patients were treated with antiplatelet therapy consisting of aspirin $325 \mathrm{mg}$ daily unless it was felt to be contraindicated by the attending of record in accordance with the Guidelines for the Management of Acute Cervical Spine and Spinal Cord Injuries. ${ }^{6}$ No patient underwent endovascular therapy for treatment of a VA occlusion.

\section{Statistical Analysis}

Statistical analysis was performed using $\mathrm{R}$ statistics (version 3.1.1, http://www.r-project.org). Our primary outcome of interest was ischemic stroke attributable to VA occlusion. Patients with ischemic stroke were regarded as recipients of cervical spine manipulation and/or antiplatelet therapy only if these interventions were performed prior to onset of ischemia. In univariate analysis, variables were compared between groups using the Wilcoxon ranksum test for numerical variables and Fisher exact test for categorical variables. Statistical significance was defined as $p<0.05$. Multivariate logistic regression was performed to determine if cervical spine surgery was independently associated with ischemic stroke after controlling for potential confounding variables such as age and degree of VA occlusion.

Patients diagnosed with an ischemic stroke prior to cervical intervention were excluded from analysis evaluating the effect of cervical intervention on stroke rate.

\section{Results}

Fifty-two patients with VA occlusion due to high-energy blunt trauma were identified. The average age was 51.1 years. There were $48(92.3 \%)$ unilateral VA occlusions and $4(7.7 \%)$ bilateral VA injuries (2 bilateral occlusions and 2 unilateral occlusions with contralateral dissections). The occluded VA segments were $V_{1}$ in 12 cases (22.2\%), $\mathrm{V}_{2}$ in 31 cases $(57.4 \%), \mathrm{V}_{3}$ in 10 cases $(18.5 \%)$, and $\mathrm{V} 4$ in 1 case $(1.9 \%$ ) (54 total VA occlusions). Motor vehicle collision (73.1\%) was the most common mechanism of injury, and a traumatic cervical spine fracture (92.3\%) was the most common risk factor prompting screening CTA of the neck. Fifteen patients (28.8\%) suffered a cervical spine subluxation and 18 (34.6\%) suffered a spinal cord injury. Halo vest, closed reduction, and surgery were performed in 19 (36.5\%), 14 (26.9\%), and 27 (51.9\%) patients, respectively. Surgery consisted of internal fixation and fusion in $26(96.3 \%)$ cases and decompression in $1(3.7 \%)$. Antiplatelet therapy was used in $42(80.8 \%)$ patients. Ten $(19.2 \%)$ patients suffered an ischemic stroke attributable to a VA occlusion; 7 of the strokes were symptomatic, and 2 resulted in death (Table 1).

\section{Patients With Vertebrobasilar Ischemia}

Univariate analysis demonstrated significant differences among patients with stroke attributable to VA occlusion and those without stroke with respect to age and cervical spinal surgery. The 10 stroke patients were significantly older (61.6 vs 48.6 years, $p=0.042$ ) and underwent significantly less spine surgery (10\% with stroke vs $61.9 \%$ without stroke, $\mathrm{p}<0.005$ ) (Table 2).

Multivariable logistic regression also demonstrated significantly fewer ischemic strokes in patients treated with spine surgery (OR 0.049 [95\% CI 0.014-0.167], $\mathrm{p}=0.014$ ). There was a trend toward increased stroke risk with advancing patient age and bilateral VA injury (bilateral occlusion or unilateral occlusion with contralateral dissection) (Table 3).

\section{Patients Treated With Cervical Spine Surgery}

Patients treated with cervical spine surgery had significantly fewer ischemic strokes $(3.7 \%$ vs $36 \%, \mathrm{p}<0.0005)$ and symptomatic ischemic strokes $(3.7 \%$ vs $24 \%, \mathrm{p}=$ 0.046). Additionally, patients undergoing cervical spine surgery suffered more cervical spine subluxations $(48.1 \%$ vs $8 \%, \mathrm{p}<0.005)$ and spinal cord injuries $(59.3 \%$ vs $8 \%$, p $<0.0005)$ and were more likely to be treated with a halo (70.4\% vs $0 \%, \mathrm{p}<0.0001)$ (Table 4). 
TABLE 1. Characteristics in 52 patients included in this series

\begin{tabular}{|c|c|}
\hline Characteristic & Value* $^{*}$ \\
\hline \multicolumn{2}{|l|}{ Sex } \\
\hline Male & $38(73.1)$ \\
\hline Female & $14(26.9)$ \\
\hline Mean age in yrs $( \pm S D)$ & $51.1 \pm 19.9$ \\
\hline \multicolumn{2}{|l|}{ VAI } \\
\hline Unilateral occlusion & $48(92.3)$ \\
\hline Bilateral injury & $4(7.7)$ \\
\hline Dissection & $2(3.8)$ \\
\hline \multicolumn{2}{|l|}{ Type of CSI } \\
\hline Fracture & $48(92.3)$ \\
\hline Subluxation & $15(28.8)$ \\
\hline $\mathrm{SCl}$ & $18(34.6)$ \\
\hline \multicolumn{2}{|l|}{ Cervical intervention $\dagger$} \\
\hline Closed reduction $\ddagger$ & $14(26.9)$ \\
\hline Spinal surgery§ & $27(51.9)$ \\
\hline Antiplatelets $\mathbb{T}$ & $42(80.8)$ \\
\hline Halo vest & $19(36.5)$ \\
\hline \multicolumn{2}{|l|}{ Mechanism of injury } \\
\hline MVC & $38(73.1)$ \\
\hline PCA & $2(3.8)$ \\
\hline Football injury & $1(1.9)$ \\
\hline Fall & $11(21.2)$ \\
\hline Ischemic stroke attributable to VAI & $10(19.2)$ \\
\hline Symptomatic stroke & $7(13.5)$ \\
\hline \multicolumn{2}{|l|}{ Mortality } \\
\hline Alive & $47(90.4)$ \\
\hline Death attributable to stroke & $2(3.8)$ \\
\hline Death not attributable to stroke & $3(5.8)$ \\
\hline
\end{tabular}

$\mathrm{CSI}=$ cervical spine injury; GOS = Glasgow Outcome Scale; MVC = motor vehicle collision; $\mathrm{PCA}=$ pedestrian-car accident; $\mathrm{SCI}$ = spinal cord injury; VAI $=$ VA injury.

* Values are presented as the number of patients (\%) unless noted otherwise. $\dagger$ Cervical intervention before onset of ischemia or in patients without ischemic stroke.

$\ddagger$ All patients treated with closed reduction subsequently underwent spinal surgery.

$\S$ With and without prior closed reduction.

I Antiplatelets administered before onset of ischemia or to patients without ischemic stroke.

\section{Patients Treated With Closed Reduction}

Patients treated with closed reduction of the cervical spine had significantly more cervical spine subluxations $(92.9 \%$ vs $0 \%, \mathrm{p}<0.0001)$ and halo vests $(100 \%$ vs $38.5 \%$, $\mathrm{p}<0.0005)$ (Table 5).

\section{Discussion}

Traumatic VA occlusion is an increasingly recognized complication of traumatic cervical spine injury with an incidence of approximately 10\%.4,7,15 Vertebral artery occlusion is an established risk factor for vertebrobasilar ischemia through mechanisms of hemodynamic failure and thromboembolism. The impact of cervical spine manipulation on stroke rate in this setting is not known. Anecdotal reports of patients suffering an ischemic stroke following cervical reduction or surgery have led some to
TABLE 2. Characteristics of patients with and without stroke

\begin{tabular}{|c|c|c|c|}
\hline Characteristics & $\begin{array}{c}\text { Stroke } \\
(n=10)^{*}\end{array}$ & $\begin{array}{c}\text { No Stroke } \\
(n=42)^{*}\end{array}$ & $\begin{array}{c}p \\
\text { Value }\end{array}$ \\
\hline \multicolumn{4}{|l|}{ Sex } \\
\hline Male & $7(70.0)$ & $31(73.8)$ & 1 \\
\hline Female & $3(30.0)$ & $1126.2)$ & \\
\hline Mean age in yrs $( \pm S D)$ & $61.6 \pm 20.9$ & $48.6 \pm 19.0$ & 0.042 \\
\hline \multicolumn{4}{|l|}{ VA occlusion } \\
\hline Unilateral occlusion & $8(80.0)$ & $40(95.2)$ & 0.163 \\
\hline Bilateral injury & $2(20.0)$ & $2(4.8)$ & \\
\hline \multicolumn{4}{|l|}{ VA dissection } \\
\hline Yes & $1(10.0)$ & $1(2.4)$ & 0.351 \\
\hline No & $9(90.0)$ & $41(97.6)$ & \\
\hline \multicolumn{4}{|l|}{ Type of CSI } \\
\hline Fracture & $9(90.0)$ & $39(92.9)$ & 1 \\
\hline Subluxation & $2(20.0)$ & $13(31.0)$ & 0.704 \\
\hline $\mathrm{SCl}$ & $1(10.0)$ & $17(40.5)$ & 0.136 \\
\hline \multicolumn{4}{|l|}{ Cervical intervention } \\
\hline Closed reduction & $1(10.0)$ & $13(31.0)$ & 0.254 \\
\hline Spinal surgery & $1(10.0)$ & $26(61.9)$ & $<0.005$ \\
\hline \multicolumn{4}{|l|}{ Antiplatelet therapy } \\
\hline Yes & $8(80.0)$ & $34(81.0)$ & 1 \\
\hline No & $2(20.0)$ & $8(19.0)$ & \\
\hline \multicolumn{4}{|l|}{ Halo vest } \\
\hline Yes & $1(10.0)$ & $18(42.9)$ & 0.072 \\
\hline No & $9(90.0)$ & $24(57.1)$ & \\
\hline \multicolumn{4}{|l|}{ Mechanism of injury } \\
\hline MVC & $6(60.0)$ & $32(76.2)$ & \\
\hline PCA & $1(10.0)$ & $1(2.4)$ & 0.136 \\
\hline Football injury & $1(10.0)$ & $0(0.0)$ & \\
\hline Fall & $2(20.0)$ & $9(21.4)$ & \\
\hline \multicolumn{4}{|l|}{ Mortality } \\
\hline Alive & $8(80.0)$ & $39(92.9)$ & \\
\hline Death attributable to stroke & $2(20.0)$ & $0(0.0)$ & 0.039 \\
\hline Death not attributable to stroke & $0(0.0)$ & $3(7.1)$ & \\
\hline
\end{tabular}

* Values are presented as the number of patients (\%) unless noted otherwise.

believe that cervical spine manipulation increases the risk of ischemic stroke. Others hypothesize that operative fixation reduces the risk by stabilizing the spine and decompressing the vessel, thus diminishing the potential for clot propagation. ${ }^{11,16}$ Data regarding this issue are limited. The present series of 52 patients is the largest study evaluating the relationship between ischemic stroke from traumatic VA occlusion and cervical spine surgery.

\section{Vertebrobasilar Ischemia}

Ten patients $(19.2 \%)$ suffered an ischemic stroke attributable to a traumatically occluded VA. This rate is comparable to previous studies reporting a range of $7.1 \%-33.3 \% .^{1,10,12,14}$ It is important to note that despite the robust collateral circulation of the posterior fossa, patients with traumatic VA occlusion are at high risk for ischemic stroke. While hemodynamic failure is a plausible etiology in bilateral VA occlusion $(50 \%$ stroke rate in this and a previously reported series ${ }^{10}$ ), and in patients with thrombosis of the dominant VA, thromboembolism appears as the likely culprit in the majority of patients..$^{5,8,10,13}$ While 
TABLE 3. Independent predictors of ischemic stroke

\begin{tabular}{lrrrr}
\hline \multicolumn{1}{c}{ Predictor } & $\begin{array}{c}\text { Multivariate } \\
\text { Coefficient }\end{array}$ & SE & OR $(95 \% \mathrm{Cl})$ & $\begin{array}{c}\mathrm{p} \\
\text { Value }\end{array}$ \\
\hline Spinal surgery & -3.025 & 1.236 & $0.049(0.014-0.167)$ & 0.014 \\
\hline Age & 0.045 & 0.024 & $1.05(1.02-1.07)$ & 0.065 \\
\hline Bilateral VA injury & 2.583 & 1.492 & $13.2(2.98-58.9)$ & 0.084 \\
\hline
\end{tabular}

some reports have marginalized the clinical consequences of these strokes, often identifying asymptomatic or functionally insignificant areas of ischemia, ${ }^{10,15}$ others have described significant morbidity and mortality. ${ }^{12}$ Our series supports the latter with 7 of 10 strokes being symptomatic,

TABLE 4. Characteristics of patients who underwent spinal surgery

\begin{tabular}{|c|c|c|c|}
\hline Characteristics & $\begin{array}{c}\text { Spinal } \\
\text { Surgery } \\
(n=27)^{*}\end{array}$ & $\begin{array}{c}\text { No Spinal } \\
\text { Surgery } \\
(n=25)^{*}\end{array}$ & $\mathrm{p}$ Value \\
\hline \multicolumn{4}{|l|}{ Sex } \\
\hline Male & $21(77.8)$ & $17(68.0)$ & 0.536 \\
\hline Female & $6(22.2)$ & $8(32.0)$ & \\
\hline Mean age in yrs $( \pm S D)$ & $51.0 \pm 17.2$ & $51.2 \pm 22.8$ & 0.840 \\
\hline \multicolumn{4}{|l|}{ VA occlusion } \\
\hline Unilateral occlusion & $25(92.6)$ & $23(92.0)$ & 1 \\
\hline Bilateral injury & $2(7.4)$ & $2(8.0)$ & \\
\hline \multicolumn{4}{|l|}{ VA dissection } \\
\hline Yes & $1(3.7)$ & $1(4.0)$ & 1 \\
\hline No & $26(96.3)$ & $24(96.0)$ & \\
\hline \multicolumn{4}{|l|}{ Type of CSI } \\
\hline Fracture & $26(96.3)$ & $22(88.0)$ & 0.341 \\
\hline Subluxation & $13(48.1)$ & $2(8.0)$ & $<0.005$ \\
\hline $\mathrm{SCl}$ & $16(59.3)$ & $2(8.0)$ & $<0.0005$ \\
\hline \multicolumn{4}{|l|}{ Antiplatelet therapy } \\
\hline Yes & $21(77.8)$ & $21(84.0)$ & 0.729 \\
\hline No & $6(22.2)$ & $4(16.0)$ & \\
\hline \multicolumn{4}{|l|}{ Halo vest } \\
\hline Yes & $19(70.4)$ & $0(0.0)$ & $<0.0001$ \\
\hline No & $8(29.6)$ & $25(100.0)$ & \\
\hline \multicolumn{4}{|l|}{ Mechanism of injury } \\
\hline MVC & $18(66.7)$ & $20(80.0)$ & \\
\hline PCA & $0(0.0)$ & $2(8.0)$ & 0.151 \\
\hline Football injury & $1(3.7)$ & $0(0.0)$ & \\
\hline Fall & $8(29.6)$ & $3(12.0)$ & \\
\hline \multicolumn{4}{|l|}{ Ischemic stroke } \\
\hline Yes & $1(3.7)$ & $9(36.0)$ & $<0.0005$ \\
\hline No & $26(96.3)$ & $16(64.0)$ & \\
\hline \multicolumn{4}{|l|}{ Symptomatic stroke } \\
\hline Yes & $1(3.7)$ & $6(24.0)$ & 0.046 \\
\hline No & $26(96.3)$ & $19(76.0)$ & \\
\hline \multicolumn{4}{|l|}{ Mortality } \\
\hline Alive & $26(96.3)$ & $21(84.0)$ & \\
\hline Death attributable to stroke & $0(0.0)$ & $2(8.0)$ & 0.315 \\
\hline $\begin{array}{l}\text { Death not attributable to } \\
\text { stroke }\end{array}$ & $1(3.7)$ & $2(8.0)$ & \\
\hline
\end{tabular}

\footnotetext{
* Values are presented as the number of patients (\%) unless noted otherwise.
}

TABLE 5. Characteristics of patients who underwent closed reduction

\begin{tabular}{|c|c|c|c|}
\hline Characteristics & $\begin{array}{l}\text { Spinal Surgery } \\
\text { w/ Closed } \\
\text { Reduction } \\
n=14)^{*}\end{array}$ & $\begin{array}{l}\text { Spinal Surgery } \\
\text { Only }(n=13)^{*}\end{array}$ & $\begin{array}{c}p \\
\text { Value }\end{array}$ \\
\hline \multicolumn{4}{|l|}{ Sex } \\
\hline Male & $9(64.3)$ & $12(92.3)$ & \multirow[t]{2}{*}{0.165} \\
\hline Female & $5(35.7)$ & $1(7.7)$ & \\
\hline Mean age in yrs ( \pm SD) & $46.9 \pm 15.9$ & $55.5 \pm 17.9$ & 0.190 \\
\hline \multicolumn{4}{|l|}{ VA occlusion } \\
\hline Unilateral occlusion & $13(92.9)$ & $12(92.3)$ & \multirow[t]{2}{*}{1} \\
\hline Bilateral injury & $1(7.1)$ & $1(7.7)$ & \\
\hline \multicolumn{4}{|l|}{ VA dissection } \\
\hline Yes & $1(7.1)$ & $0(0.0)$ & \multirow[t]{2}{*}{1} \\
\hline No & $13(92.9)$ & $13(100.0)$ & \\
\hline \multicolumn{4}{|l|}{ Outcomes } \\
\hline Ischemic stroke & $1(7.1)$ & $0(0.0)$ & 1 \\
\hline Symptomatic stroke & $1(7.1)$ & $0(0.0)$ & 1 \\
\hline \multicolumn{4}{|l|}{ Type of CSI } \\
\hline Fracture & $13(92.9)$ & $13(100.0)$ & 1 \\
\hline Subluxation & $13(92.9)$ & $0(0.0)$ & $<0.0001$ \\
\hline $\mathrm{SCl}$ & $10(71.4)$ & $6(46.2)$ & 0.252 \\
\hline \multicolumn{4}{|l|}{ Antiplatelet therapy } \\
\hline Yes & $10(71.4)$ & $11(84.6)$ & \multirow[t]{2}{*}{0.648} \\
\hline No & $4(28.6)$ & $2(15.4)$ & \\
\hline \multicolumn{4}{|l|}{ Halo vest } \\
\hline Yes & $14(100.0)$ & $5(38.5)$ & \multirow[t]{2}{*}{$<0.0005$} \\
\hline No & $0(0.0)$ & $8(61.5)$ & \\
\hline \multicolumn{4}{|l|}{ Mechanism of injury } \\
\hline MVC & $9(64.3)$ & $9(69.2)$ & \multirow{4}{*}{1} \\
\hline PCA & $0(0.0)$ & $0(0.0)$ & \\
\hline Football injury & $1(7.1)$ & $0(0.0)$ & \\
\hline Fall & $4(28.6)$ & $4(30.8)$ & \\
\hline \multicolumn{4}{|l|}{ Mortality } \\
\hline Alive & $14(100.0)$ & $12(92.3)$ & \multirow{3}{*}{0.482} \\
\hline $\begin{array}{l}\text { Death attributable to } \\
\text { stroke }\end{array}$ & $0(0.0)$ & $0(0.0)$ & \\
\hline $\begin{array}{l}\text { Death not attributable } \\
\text { to stroke }\end{array}$ & $0(0.0)$ & $1(7.7)$ & \\
\hline
\end{tabular}

* Values are presented as the number of patients (\%) unless noted otherwise.

including 2 deaths directly attributable to vertebrobasilar ischemia.

\section{Cervical Spine Manipulation and Vertebrobasilar Ischemia}

The effect of cervical spine manipulation for the treatment of cervical spine fractures and subluxations on stroke rate in the presence of a traumatic VA occlusion is not known. Plausible arguments can be made for cervical spine manipulation as a risk factor and a protective factor. Perhaps the cervical manipulation that occurs with closed reduction and surgery further damages the vessel, propagates thrombus, and mobilizes emboli. Alternatively, it is conceivable that cervical reduction and surgery restores proper alignment, indirectly decompresses the injured vessel, and diminishes the chance of distal emboli or hemodynamic failure. Data from this series support the 
latter scenario. Cervical spine surgery (with or without preceding closed reduction) was significantly associated with a decreased risk of ischemic stroke in both univariate analysis $(\mathrm{p}<0.005)$ and multivariate logistic regression (OR 0.049 [95\% CI 0.014-0.167], $\mathrm{p}=0.014$ ). Clinical implications include assurance that treatment of a cervical spine injury in the setting of a VA occlusion is safe, prompt recognition and treatment of cervical spine injury is recommended to diminish the risk of vertebrobasilar ischemia, and the presence of a VA occlusion should be considered in the decision making process whether to perform cervical surgery particularly if the indication is debatable.

\section{Risk Factors for Vertebrobasilar Ischemia}

Univariate analysis identified increasing age as a significant risk factor for ischemic stroke in the setting of a traumatically occluded VA $(\mathrm{p}=0.042)$. Multivariate logistic regression analysis demonstrated a trend toward increased risk with increasing age (OR 1.05 for each additional year, $\mathrm{p}=0.065)$. Previous authors have also noted this finding in patients with known cervical spine injuries. ${ }^{3}$ Older patients are more likely to have preexisting comorbidities, atherosclerosis, and relatively poor collateral circulation, placing them at increased risk of stroke with acute traumatic occlusion of a VA.

The presence of bilateral VA injury (bilateral occlusion or unilateral occlusion with contralateral dissection) also trended toward significance in multivariate logistic regression analysis (OR 13.2 [95\% CI 2.98-58.9], $\mathrm{p}=$ $0.084)$. Half of patients with bilateral VA injuries suffered an ischemic event, echoing the finding of another recent study. ${ }^{10}$ The lack of statistical significance is likely a product of Type II error due to the small number of bilateral VA injuries in this series.

\section{Future Direction}

Nearly 1 in 5 patients with a traumatically occluded VA experienced an ischemic stroke in this series. Seventy percent of stroke patients were symptomatic and 2 died of stroke-related deaths. While cervical spine surgery was shown to be protective, perhaps the medical management of these patients needs to be revisited. The 3 most contemporary and largest series of traumatic VA occlusion (including the current series) used antiplatelet therapy as the first-line treatment. ${ }^{10,12}$ Despite a stroke rate of only $10.8 \%$, all of which were asymptomatic, Morton et al. concluded that prophylactic antiplatelet medication should not be used regularly. ${ }^{10}$ This conclusion was made after observing that stroke rates and emboli detection were not significantly altered following antiplatelet administration. ${ }^{10} \mathrm{Scott}$ et al. reported a stroke rate of $7.1 \%$ but hypothesized that the cerebral infarcts occurred in the immediate postinjury period and thus were present on admission..$^{12}$ The current series also failed to identify a significant difference in the use of antiplatelets between patients with and without stroke. Future investigation should focus on novel therapies for the management of traumatically occluded VAs; possibilities include dual antiplatelet therapy, systemic anticoagulation, and endovascular intervention.

\section{Limitations}

This is a retrospective study observational without a control group; thus, there may be potential confounders that have not been identified. Reliable information about the temporal relationship between traumatic VA occlusion and the subsequent ischemic stroke was not available due to 1) multisystem traumatic injury limiting patient reporting of symptoms and preventing detailed neurological examinations; 2) presence of clinically silent ischemic strokes; 3) critically ill patients unable to undergo prompt diagnostic imaging; and 4) retrospective data collection. Despite this being the largest single series of patients with traumatic VA occlusions, the numbers are small, introducing the potential for a Type II error. Despite liberal screening criteria at the institution guided by the Denver ${ }^{2} /$ Memphis ${ }^{9}$ criteria, it is possible that asymptomatic VA occlusions were missed. It is also possible that asymptomatic VA distribution ischemic strokes were missed because MR images and CT scans were only obtained when clinically indicated. Last, this is a single institution experience and should be generalized with caution.

\section{Conclusions}

Traumatic occlusion of the VA is associated with a substantial risk of ischemic stroke, neurological morbidity, and mortality. While advancing age and bilateral VA injury appear to increase the risk of vertebrobasilar ischemia, corrective cervical spine surgery potentially reduces the risk. Potential explanations for this protective effect include spinal stabilization thereby reducing motion and ongoing local arterial trauma, as well as, indirect arterial decompression. Though a high stoke risk may be inherent to these traumatic injuries, novel therapies (i.e., dual antiplatelets, anticoagulants, endovascular intervention) should be investigated in an attempt to reduce their occurrence.

\section{References}

1. Biffl WL, Moore EE, Elliott JP, Ray C, Offner PJ, Franciose RJ, et al: The devastating potential of blunt vertebral arterial injuries. Ann Surg 231:672-681, 2000

2. Biffl WL, Moore EE, Offner PJ, Brega KE, Franciose RJ, Elliott JP, et al: Optimizing screening for blunt cerebrovascular injuries. Am J Surg 178:517-522, 1999

3. Chikuda H, Ohya J, Horiguchi H, Takeshita K, Fushimi K, Tanaka S, et al: Ischemic stroke after cervical spine injury: analysis of 11,005 patients using the Japanese Diagnosis Procedure Combination database. Spine J 14:2275-2280, 2014

4. Giacobetti FB, Vaccaro AR, Bos-Giacobetti MA, Deeley DM, Albert TJ, Farmer JC, et al: Vertebral artery occlusion associated with cervical spine trauma. A prospective analysis. Spine (Phila Pa 1976) 22:188-192, 1997

5. Griessenauer CJ, Fleming JB, Richards BF, Cava LP, Curé $\mathrm{JK}$, Younan DS, et al: Timing and mechanism of ischemic stroke due to extracranial blunt traumatic cerebrovascular injury. J Neurosurg 118:397-404, 2013

6. Harrigan MR, Hadley MN, Dhall SS, Walters BC, Aarabi B, Gelb DE, et al: Management of vertebral artery injuries following non-penetrating cervical trauma. Neurosurgery 72 (Suppl 2):234-243, 2013

7. Jang JW, Lee JK, Hur H, Seo BR, Lee JH, Kim SH: Vertebral artery injury after cervical spine trauma: A prospective 
study using computed tomographic angiography. Surg Neurol Int 2:39, 2011

8. Kawano H, Inatomi Y, Hirano T, Yonehara T: Vertebral artery stump syndrome in acute ischemic stroke. J Neurol Sci 324:74-79, 2013

9. Miller PR, Fabian TC, Croce MA, Cagiannos C, Williams JS, Vang M, et al: Prospective screening for blunt cerebrovascular injuries: analysis of diagnostic modalities and outcomes. Ann Surg 236:386-395, 2002

10. Morton RP, Hanak BW, Levitt MR, Fink KR, Peterson EC, Vilela MD, et al: Blunt traumatic occlusion of the internal carotid and vertebral arteries. J Neurosurg 120:1446-1450, 2014

11. Rodriguez M, Tyberghien A, Matgé G: Asymptomatic vertebral artery injury after acute cervical spine trauma. Acta Neurochir (Wien) 143:939-945, 2001

12. Scott WW, Sharp S, Figueroa SA, Eastman AL, Hatchette CV, Madden CJ, et al: Clinical and radiological outcomes following traumatic Grade 3 and 4 vertebral artery injuries: a 10-year retrospective analysis from a Level I trauma center. The Parkland Carotid and Vertebral Artery Injury Survey. J Neurosurg 122:1202-1207, 2015

13. Srinivasan J, Newell DW, Sturzenegger M, Mayberg MR, Winn HR: Transcranial Doppler in the evaluation of internal carotid artery dissection. Stroke 27:1226-1230, 1996

14. Stein DM, Boswell S, Sliker CW, Lui FY, Scalea TM: Blunt cerebrovascular injuries: does treatment always matter? J Trauma 66:132-143, discussion 143-144, 2009
15. Taneichi H, Suda K, Kajino T, Kaneda K: Traumatically induced vertebral artery occlusion associated with cervical spine injuries: prospective study using magnetic resonance angiography. Spine (Phila Pa 1976) 30:1955-1962, 2005

16. Veras LM, Pedraza-Gutiérrez S, Castellanos J, Capellades J, Casamitjana J, Rovira-Cañellas A: Vertebral artery occlusion after acute cervical spine trauma. Spine (Phila Pa 1976) 25:1171-1177, 2000

\section{Author Contributions}

Conception and design: Foreman, Griessenauer, Harrigan. Acquisition of data: Foreman, Griessenauer. Analysis and interpretation of data: Foreman, Griessenauer, Chua, Harrigan. Drafting the article: Foreman, Griessenauer. Critically revising the article: Foreman, Griessenauer, Chua, Hadley, Harrigan. Reviewed submitted version of manuscript: Foreman, Griessenauer, Hadley, Harrigan. Statistical analysis: Chua. Administrative/technical/material support: Foreman, Griessenauer, Hadley, Harrigan. Study supervision: Foreman, Griessenauer, Hadley, Harrigan.

\section{Correspondence}

Paul M. Foreman, Department of Neurosurgery, University of Alabama at Birmingham, Faculty Office Tower 1005, 510 20th St. S, Birmingham, AL 35294. email: pforeman03@gmail.com. 